working of the Convention, and the possibility of bringing about complete cessation of discharge of persistent oils into the sea. In resolving to take over its functions, however, the Organization pointed out to the governments concerned that, owing to other urgent tasks, it would not be possible to convene a further conference before 1961. Mr. Böös ended on a personal note, stating that though the convening of a further conference on oil pollution was not an obligation made under the Convention, he would characterize it as a moral undertaking inspired by the first resolution of the 1954 Conference. The aim of that resolution was certainly the same as the object of the present conference, namely, the complete avoidance of discharge of persistent oils into the sea, which, so far as was known, was the only entirely effective method of preventing oil pollution.

Two resolutions were adopted by the conference. The first urged that the governments of countries which had not yet ratified the Convention of 1954 should do so ; that further efforts should be made to impress upon governments and upon ship owners and ship's officers and crews the serious consequences arising from the discharge of oily wastes into the sea ; that all necessary facilities be provided for the disposal of oily wastes in main ports and harbours; that technical research into means of avoiding dis. charges of oily wastes into the sea be intensified, and the results made widely known through the Inter-governmental Maritime Consultative Organization ; that with a view to achieving the aim of total avoidance of the discharge of persistent oils into the sea, the governments and the Organization should make preparations for holding a further inter-governmental conference as soon as possible.

The second resolution, though reiterating the only effective solution of the problem, proposed in the meantime an extension of the prohibited zones for oil discharges in such areas as the Gulf of St. Law. rence, the Grand Banks of Newfoundland, and the eastern seaboard of North America, and also in the Baltic and North Seas. P. BARclay-Smrty

\title{
RADIOACTIVATION ANALYSIS
}

$\mathrm{N}^{\mathrm{sin}}$ EW methods of chemical analysis using techniques derived from nuclear physics were discussed at a Symposium on Radioactivation Analysis held in Vienna during June 1-3. Sponsored by the International Atomic Energy Agency and the International Council of Scientific Unions, the meeting brought together research workers from twenty-one countries for the first international conference on a subject of rapidly growing importance in many branches of science, medicine and industry.

An introductory survey by G. B. Cook (Atomic Energy Research Establishment, Harwell) was followed by reviews of the uses of activation analysis in geochemistry (W. Herr, Max-Planck Institute of Chemistry, Mainz), biochemistry and medicine (J. M. A. Lenihan, Western Regional Hospital Board, Glasgow) and metallurgy (J. Hoste, University of Ghent). P. Leveque (Centre d'Études Nucléaires, Saclay) spoke of applications in industry and G. W. Leddicotte (Oak Ridge National Laboratory) described recent developments in the United States. Several shorter contributions were also given.

Most analytical methods depend on the behaviour of electrons. Activation analysis depends on the properties of the nucleus, in particular the radioactivity induced by bombardment with neutrons or other particles. Many elements have isotopes which decay slowly enough for the assay to be done a day or two after irradiation, but work on short-lived activities can only be done close to a neutron source. A reactor is the instrument of choice for activation analysis, but more modest facilities are often serviceable. Discharge tubes using the deuterium-tritium reaction give neutron fluxes as high as $10^{9} n / \mathrm{cm} .{ }^{2} / \mathrm{sec}$. at moderate cost. Useful work has been done with the lower fluxes provided by radium-beryllium or antimony-beryllium sources; a recent innovation is the americium-beryllium source, which has the merit of freedom from residual $\gamma$-ray emission.

Since nearly seventy elements become appreciably radioactive after a few hours exposure inside a nuclear reactor of moderate thermal neutron flux $\left(10^{12} n /\right.$ $\mathrm{cm} .{ }^{2} / \mathrm{sec}$.), the irradiated sample generally contains several different activities. Fortunately many of the common matrix elements (aluminium, silicon, iron, carbon, nitrogen, oxygen) have relatively small cross-sections for thermal neutron capture. Differences in half-life and decay energy between trace element and matrix or between different trace elements in the sample are also advantageous.

The isolation of individual activities for radio active assay may often be achieved by $\gamma$-ray spectroscopy, but a preliminary chemical separation is generally advisable, even when dealing with shortlived nuclides. When once the experimental material has been irradiated, along with a known amount of the element under investigation (to serve as a stan. dard), the isolation may be simplified by the addition of stable carrier in any desired amount. Another useful advantage of the activation method is that contamination of reagents, often a source of trouble in the micro-determination of trace elements, need not be considered at all.

The sensitivity of thermal neutron activation analysis for trace estimation is remarkable. Many elements can be estimated at levels of $10^{-8}$ to $10^{-11}$ gm. using a neutron flux of $10^{12} \mathrm{n} / \mathrm{cm} .^{2} / \mathrm{sec}$. acting on a I-gm. sample. The detection of trace elements by this method has been useful in several industrial problems, notably the measurement of deliberate or fortuitous contamination in semi-conductor materials. Applications in the oil industry are so numerous (and so important financially) that many companies have acquired neutron sources of their own. A typical problem, in which conventional methods of analysis are not sufficiently sensitive, is the control of vanadium, which acts as a catalyst poison in cracking operations and as a corrosive agent in fuel oils.

The same element is important in a different connexion as a constituent of high-alloy steels. Here the activation method of analysis is valuable for its speed and accuracy. A 10-second irradiation, at a flux of $10^{10} \mathrm{n} / \mathrm{cm} .^{2} / \mathrm{sec}$., is sufficient for analytical determinations using the isotope vanadium-52 (half-life $3 \cdot 8$ minutes). In prospecting for vanadium, a useful technique is to lower into a borehole a neutron 
generator. After a few minutes the generator is replaced by a scintillation counter to estimate the vanadium -52 activity.

In geochemistry, where the study of natural radioactivity has been of prime importance for more than half a century, the new possibilities offered by activation analysis have been welcomed. A powerful technique for age determination in rocks and meteorites depends on measurement of the relative abund ance of parent and daughter nuclides in a natural radioactive decay process. Useful improvement in sensitivity can be expected where one or both of the nuclides can be subjected to activation analysis. Potassium/argon and rubidium/strontium ratios are readily measured in this way. Uranium-238 can be estimated down to a limit of $10^{-12} \mathrm{gm}$. by the reaction ${ }^{238} \mathrm{U}(n, \gamma \beta)^{239} \mathrm{~Np}$. For uranium-235 the limit of sensitivity so far achieved (at the Argonne National Laboratory) is $5 \times 10^{-11} \mathrm{gm}$., using the reaction ${ }^{235} \mathrm{U}(n, f){ }^{140} \mathrm{Ba}$.

Activation analysis of biological material has attracted relatively little attention, though the method has many interesting potentialities. Several elements, including vanadium, manganese and cobalt, are important to plants or animals but their function in human nutrition is still obscure, through lack of sufficiently sensitive analytical methods. The role of vanadium in dental caries and of manganese in bone formation were two of the subjects suggested for study by activation analysis. Many problems in dental science and in animal biochemistry are also awaiting exploration by activation methods.

Arsenic is an element of continuing interest in clinical science, partly because of its increasing uses and hazards in agriculture and partly because it is the only component of tobacco smoke known to be carcinogenic in man. Arsenic-levels in normal tissue are too low for accurate estimation in living subjects by conventional methods. Activation analysis has been used in several investigations of arsenic poisoning, whether accidental or homicidal. An unusual toxicological experiment was the recent study by activation analysis of the remains of Erik XIV, a sixteenth-century Swedish king who died in mysterious circumstances. These tests gave support to the theory that he was poisoned by mercury, said to have been administered in a dish of pea soup.

Although thermal neutrons are the most versatile agents for activation analysis, fast neutrons have some distinctive applications. The estimation of traces of oxygen has been done satisfactorily by mixing the experimental sample with lithium fluoride and irradiating with fast neutrons to produce the reaction ${ }^{6} \mathrm{Li}(n, \alpha){ }^{3} \mathrm{H}$ followed by ${ }^{18} \mathrm{O}\left({ }^{3} \mathrm{H}, n\right){ }^{18} \mathrm{~F}$ (halflife $112 \mathrm{~min}$.). The limit of sensitivity of this method, as practised at Harwell, is $5 \times 10^{-7} \mathrm{gm}$. of oxygen. Protons have been used for the estimation of boron in silicon, a test of considerable importance to transistor manufacturers. Neutron activation yields no suitable isotopes but fast protons induce the reac. tion ${ }^{11} \mathrm{~B}(p, n){ }^{11} \mathrm{C}$ (half-life $20.4 \mathrm{~min}$.). The silicon provides an internal standard by the reaction ${ }^{30} \mathrm{Si}(p, n)^{30} \mathrm{P}$. Concentrations of boron as low as 1 in $10^{9}$ have been measured in this way. Proton activation is useful also for the estimation of boron in germanium. Deuterons provide the best method for the estimation of magnesium in iron, by the reaction ${ }^{24} \mathrm{Mg}(d, \alpha)^{22} \mathrm{Na}$. An internal standard is given by the reaction ${ }^{56} \mathrm{Fe}(d, \alpha)^{54} \mathrm{Mn}$.

Two conclusions emerged from the symposium. The first is that any laboratory using conventional methods of chemical or spectrographic analysis would do well to explore the possible advantages of activation methods for some of its work. The second is that activation analysis, though superficially a simple technique, requires considerable skill in nuclear physics and in analytical chemistry for the full realization of its possibilities.

The success of the meeting was enhanced by the genial hospitality of the sponsors and by the agreeable atmosphere of the magnificent new conference suite of the International Atomic Energy Agency in the Hofburg. The proceedings of the symposium will be published shortly in book form. A longawaited manual of experimental procedures is in an advanced state of preparation at Oak Ridge.

J. M. A. LeniHaN

\section{THE CAPE TOWN SCIENCE EXHIBITION, 1959}

$\mathrm{E}^{\mathrm{n}}$ NCOURAGED by the success of the Science Exhibition held in Cape Town in March 1958, the Cape Council of the South African Association for the Advancement of Science, in collaboration with the Royal Society of South Africa, organized the second Science Exhibition in more spacious surroundings $(10,500$ sq. ft.) during the period April 6-11. After introductory addresses by the chairman of the Organizing Committee and vice-president of the South African Association for the Advancement of Science, Dr. Ronald Singer, and by H.M. Astronomer at the Cape, Prof. R. H. Stoy, the Exhibition was officially opened on the evening of April 6 before a distinguished audience of scientists, industrialists and educationists by His Excellency the GovernorGeneral, Dr. E. G. Jansen.

Dr. Jansen stated that the Exhibition must be of particular interest to the layman, "because although one does not always understand all that science has to teach us, one realizes the importance of seience and scientific research especially in the troublous times in which we live, and where science has, to a large extent, changed the life of civilized man and touches our everyday life at every point".

Dr. Jansen indicated that it is a rather startling thought that, according to some reports, the Soviet Union is more advanced than any other country, not only in certain fields of scientific research but also in the number of men and women receiving education and training in science and scientific methods. "The question arises as to whether sufficient is being done in that direction in our country. . . . If we believe that the future of the country is in the hands of the youth of to-day, we should surely see to it that the education of our boys and girls is in the hands of men and women most fitted for the task, and who are devoted to their work. It follows that they should 